\title{
REDESAIN ALAT KERJA PENGAMPLAS DAN HAND STRETCHING DAPAT MENURUNKAN BEBAN KERJA DAN NYERI MUSKULOSKELETAL SERTA MENINGKATKAN PRODUKTIVITAS KERJA PEKERJA BENGKEL BAGIAN PROSES PENGAMPLASAN DI DESA TENGKUDAK TABANAN
}

\author{
1I Made Astika Yasa, 2Nyoman Adiputra, 3I Nyoman Sutarja. \\ 1. Mahasiswa Program Studi Magister Ergonomi Fisiologi Kerja Uniersitas Udayana \\ 2. Staff Dosen Program Studi Magister Ergonomi Fisiologi Kerja Uniersitas Udayana \\ 3. Staff Dosen Program Studi Magister Ergonomi Fisiologi Kerja Uniersitas Udayana \\ 1Ymadeyasa87@Gmail.com, 르adip2003@yahoo.com, ${ }^{3}$ nsutarja10@yahoo.com
}

\begin{abstract}
ABSTRAK
Permasalahan ergonomi di industri bengkel bagian pengamplasan berupa sikap kerjayang tidak alamaiah dan alat kerja yang tidak ergonomis sehingga menimbulkan nyeri musculoskeletal pada pekerja pengamplas. Untuk mengatasi masalah tersebut, dilakukan penelitian dengan redesain alat kerja pengamplas dan pemberian hand stretching.

Tujuan penelitian ini adalah untuk mengetahui penggunaan redesain alat kerja pengamplas dan pemberian hand stretching pada pekerja pengamplas cat motor terhadap penurunan beban kerja, nyeri pada musculoskeletal dan produktivitas. Rancangan penelitian adalah rancangan sama subjek dengan melibatkan 12 orang pekerja pengamplas cat motor, laki-laki dengan usia 22-37 tahun, pengalaman kerja antara 2-6 tahun.

(I) subjek diberi perlakuan kerja dengan alat kerja pengamplas tanpa redesain dan tanpa pemberian hand stretching. Tahap kedua (II) subjek diberi perlakuan kerja dengan redesain alat kerja pengamplas dan pemberian hand stretching. Di antara ke dua tahap penelitian tersebut, diberikan wash out period selama 2 hari dan adaptasi redesain alat kerja pengamplas selama 4 hari, untuk menghilangkan carry over effects. Beban kerja diukur dari denyut nadi dengan metode 10 denyut, nyeri muskuloskeletal diukur dengan Visual Analogue Scale (skala 0 sampai 10) dan produktivitas kerja berdasarkan perbandingan antara output dan input. Data dianalisis dengan uji ShapiroWilk untuk mengetahui normalitas data, uji t-paired untuk menguji perbedaan kemaknaan variabel beban kerja dan produktivitas kerja pada tingkat kemaknaan $\alpha=0,05$ serta uji Wilcoxon untuk variabel keluhan muskuloskeletal.

Dari hasil penelitian menunjukkan bahwa redesain alat kerja pengamplas dan hand stretching dapat menurunkan beban kerja sebesar $8,4 \% \quad(\mathrm{p}<0,05)$ dan menurunkan nyeri muskuloskeletal sebesar $53,8 \% \quad(\mathrm{p}<0,05)$ serta meningkatkan produktivitas kerja sebesar $63,2 \%(\mathrm{p}<0,05)$. Sehingga dapat disimpulkan bahwa redesain alat kerja pengamplas dan hand stretching dapat mengurangi beban dan nyeri musculoskeletal meningkatkan produktivitas pekerja pengamplas cat motor. Disarankan kepada pemilik industri usaha sejenis agar melakukan perbaikan kondisi kerja yang mengacu pada prinsip ergonomi, sehingga tercipta kondisi kerja yang lebih aman, nyaman, sehat dan produktif bagi pekerja.
\end{abstract}

Kata kunci: $\quad$ Redesain Alat Kerja Pengamplas, Hand Stretching, Beban Kerja, Nyeri Muskuloskeletal, Produktivitas Kerja 


\section{ABSTRACT \\ REDESIGN WORKING TOOL SANDING AND HAND STRETCHING DECREASE WORKLOAD AND PAIN OF MUSCULOSKELETAL ALSO INCREASE WORK PRODUCTIVITY FOR MECHANIC WORKER ON SANDING PROCESS IN TENGKUDAK VILLAGE TABANAN}

Ergonomic problems in the workshop industry sanding in the form of work attitude which is not natural and the work tool that is not ergonomic causing musculoskeletal pain in workers sanding. To overcome these problems, conducted research with redesain sanding tools and hand stretching.

Redesain sanding tool, hand stretching for motor paint worker to decrease work load, musculoskeletal pain and increase work productivity. The design of this study is the same design of the subject by involving 12 people sanding paint motor paint, male with age 22-37 years, work experience between 2-6 years.

Research into two phases. The first phase (I) subjects are treated with a working sanding agent without redesign and without giving hand stretching. The second phase (II) subjects are treated with redesign of sanding tools and hand stretching. Between the two stages of the study, a 2-day wash out period and adaptation for redesign working tool sanding for 4-day to eliminate carry over effects. Workload is measured from the pulse with the 10 pulse method, musculoskeletal pain measured by Visual Analogue Scale (scale 0 to 10) and work productivity based on the ratio between output and input. Data were analyzed by Shapiro-Wilk test to know the normality of data, t-paired test to test the difference of significance of workload variable and work productivity on significance level $\alpha=0,05$ and Wilcoxon test for musculoskeletal complaint variable.

Redesign sanding and hand stretching tools can decrease the workload by $8.4 \%$ ( $\mathrm{p}<0.05)$ and decrease musculoskeletal complaints by 53.8\% ( $\mathrm{p}<0.05)$ and increase work productivity by $63,2 \%(\mathrm{p}<0.05)$. Redesain sanding and hand stretching tools can reduce workload and pain of musculoskeletal and increase work productivity for mechanic worker on sanding process. It is advisable to owners of similar business industries to improve the working conditions that refer to ergonomic principles, so as to create safer, more comfortable, healthy and productive working conditions for workers.

Key words: Redesign Working Tool Sanding, Hand Stretching, Workload Complaints, Work Productivity 


\section{PENDAHULUAN}

Indonesia merupakan negara pasar otomotif, beraneka ragam jenis motor ditawarkan dengan variasi harga yang berbeda. Hampir setiap hari masyarakat menggunakan motor untuk beraktivitas Menurut AISI (Asosiasi Industri Sepeda motor Indonesia), Hal ini menunjukkan bahwa banyaknya jasa servis motor yang resmi maupun tidak resmi di Indonesia begitu juga yang terjadi di wilayah Bali khususnya daerah Tabanan. Tujuannya agar konsumen dimudahkan sebagai pengguna sepeda motor dapat melakukan perawatan dari segi mesin maupun body repairing (rangka maupun cover body) sepeda motor dengan cepat dan mudah, perkembangan industri otomotif penjualan motor di tahun 2015 dari bulan Januari sampai September mencapai 4.821.191 unit dan jumlah penjualan sepeda motor.

Bengkel adalah sebuah bentuk usaha sehingga secara operasional harus menguntungkan (profitable) dan layak (feasible). Oleh karenanya seluruh kegiatan harus berorientasi kepada perolehan laba. Namun demikian perlu diingatkan bahwa laba harus diperoleh dengan cara meningkatkan produktivitas kerja, sebab jika tidak demikian justru akan sangat merugikan bengkel itu sendiri (Soedarma, 2012. Bengkel cat mempunyai banyak pekerjaan, mengamplas, dempul, cat dasar dan cat berwarna di mana terdapat banyak faktor kesehatan yang terganggu. Serta kecelakaan pekerja (Wibowo dan Djojo, 2012). Gerakan pekerja mengandalkan tangan dan pergelangan tangan secara berulang-ulang saat bekerja dapat menyebabkan terjadinya beberapa kasus penyakit yang berkaitan dengan Repetitive Strain Injury (RSI), salah satunya adalah De Quervain Syndrome.

Istilah De Quervain'ss syndrome ialah nyeri pada daerah pergelangan tangan akibat abductor pollicis longus muscle dan ecstensor pollicis breviss dengan jepitan pada kedua tendon tersebut serta pergesekan yang terlalu banyak atau lama sehingga sarung tendon menjadi radang dan menebal (Richardson dkk, 2013).

Posisi tidak alamiah memerlukan desain ulang pada stasiun kerja bagi para pekerja untuk mengurangi beban kerja yang dialami pekerja pengamplas cat motor. Berdasarkan penelitian Arimbawa (2009), redesain peralatan kerja pembuatan minyak kelapa, dari segi ergonomi didapati penurunan beban kerja sedang ke ringan yang disimpulkan dengan rerata denyut nadi kerja sebesar 16,57 denyut/menit atau sebesar $14,69 \%$ dan nyeri musculoskeletal 14,94 . 


\section{Jurnal Ergonomi Indonesia}

(The Indonesian Journal of Ergonomic)
Vol.4, No.2 : 1 Juli-Desember 2018
Upaya pencegahan untuk mengurangi tingkat nyeri pergelangan tangan pada pekerja dalam melakukan pekerjaan dapat dilakukan melalui aplikasi pendekatan ergonomi salah satunya adalah dengan pemberian latihan hand stretching atau peregangan pada tangan yang dilakukan secara aktif. Diperlukan kesiapan dari tubuh pekerja ketika akan memulai pekerjaan sehingga diharapkan dapat memperkecil atau bahkan menghilangkan nyeri muskuloskeletal. Salah satu bentuk persiapan tubuh sebelum bekerja adalah dengan melakukan peregangan atau stretching yang dapat dilakukan sendiri dengan bentuk-bentuk latihan peregangan yang sederhana. Prinsip pemberian hand stretching adalah untuk memberikan pengetahuan dan keterampilan bagi pekerja dalam melakukan pencegahan nyeri pada area lengan dan tangan. Peregan ${ }_{1} \mathrm{~g}_{4}$ an adalah aktivitas fisik yang paling sederhana dan merupakan penyeimbang sempurna untuk keadaan diam dan tidak aktif bergerak dalam waktu lama. Peregangan teratur di sela pekerjaan akan mengurangi ketegangan otot, memperbaiki peredaran darah, mengurangi kecemasan, perasaan tertekan, kelelahan, membuat pekerja merasa lebih baik (Anderson, 2010).

\section{METODE PENELITIAN}

Data dianalisis dengan uji ShapiroWilk untuk mengetahui normalitas data, uji $t$ - paired untuk menguji perbedaan kemaknaan variabel beban kerja dan produktivitas kerja pada tingkat kemaknaan $\alpha=0,05$ serta uji Wilcoxon untuk variabel keluhan muskuloskeletal.

Pekerja bengkel bagian proses pengamplasan di desa Tengkudak Tabanan berjenis kelamin laki-laki sampel diambil sebanyak 12 orang dari 18 pekerja pengamplasan cat motor dengan pengalaman kerja 1-5 tahun. Besar sample menggunakan rumus colton (1985).

\section{Variabel dan Instrumen Penelitian}

1. alat kerja pengamplasan cat motor yang digunakan untuk meratakan permukaan cover body yang diamplas dengan cara memegang, menjepit serta menekan alat amplas (sebelum redisain alat amplas) disajikan Gambar 1 sebelum redesain amplas. Gambar 2 setelah redisain alat amplas.

\section{Gambar 1}

Alat pengamplasan sebelum redisain

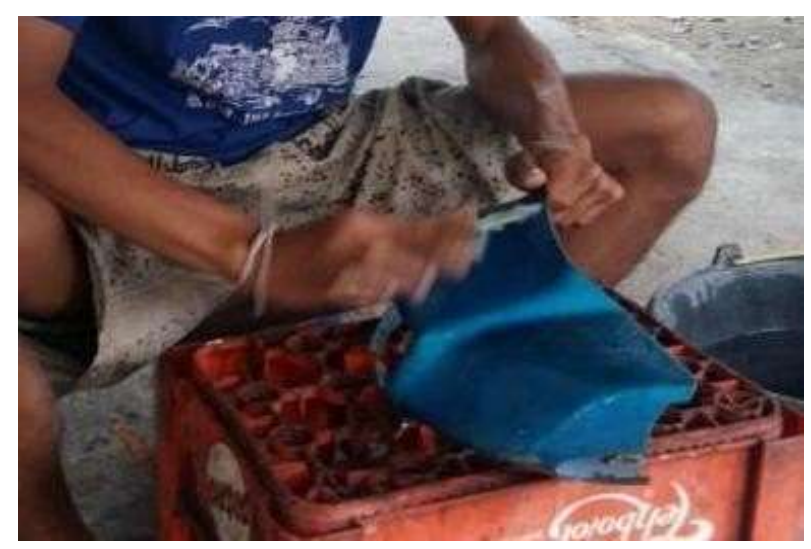


Gambar 2

Alat pengamplasan setelah redisain

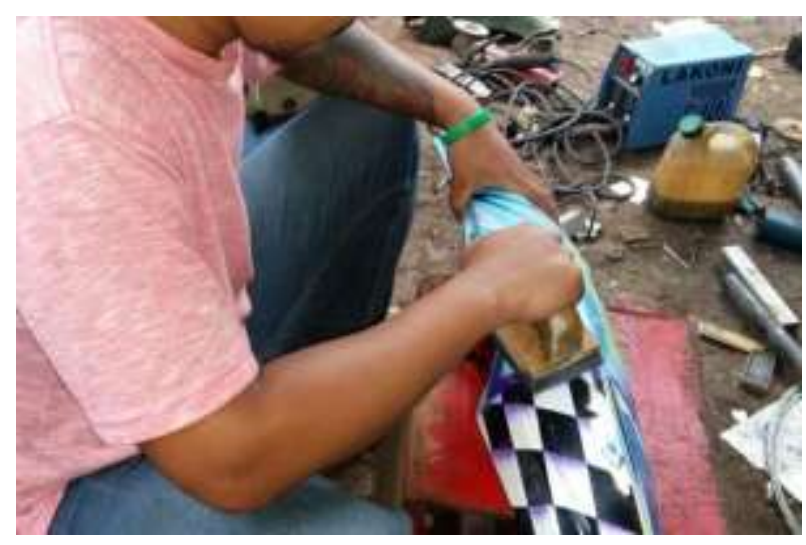

2. Nyeri muskuloskeletal pada subjek diukur dengan menggunakan Visual Analog Scale (VAS). Pengukuran tersebut bersifat subjektif. Sebelum memulai pekerjaan pada masing-masing periode, seluruh subjek diminta menunjukkan besar skala pada Visual Analog Scale yang mewakili $\mathrm{n}_{1} \mathrm{i}_{5}$ lai nyeri muskuloskeletal dialami sebelum bekerja.

3. Produktivitas kerja dihitung dengan membandingkan antara jumlah keluaran (output) dengan masukan (input) dan persatuan waktu (time).

\section{Tempat dan Waktu Penelitian}

Penelitian dilakukan pada pekerja industri kecil bengkel cat Kayan Servis di Desa Tengkudak Kabupaten Tabanan-Bali. Penelitian dan pengambilan data dilakukan pada bulan Juni dan juli 2017

\section{HASIL PENELITIAN Denyut Nadi}

Tabel 1

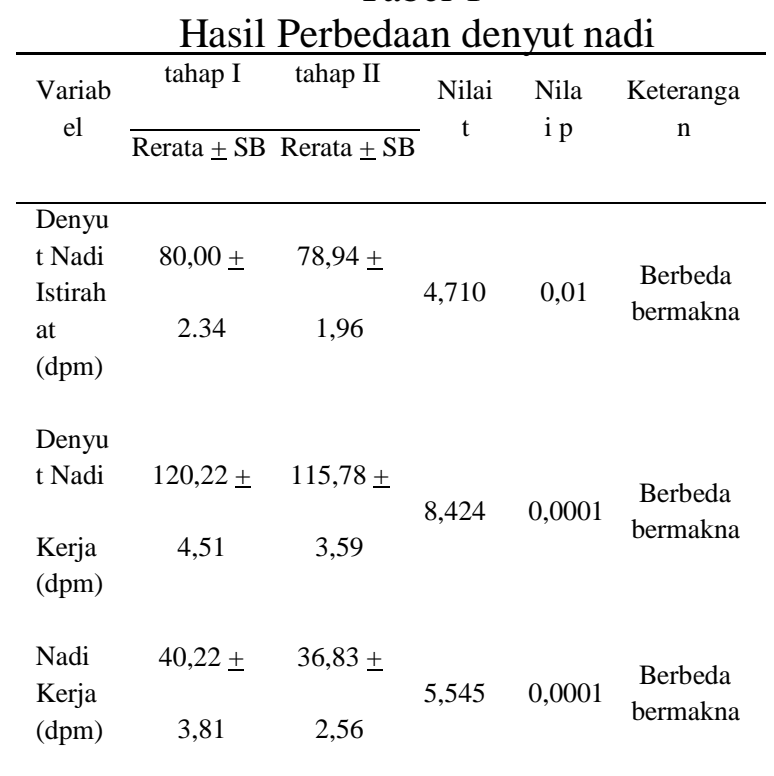

Seperti tersaji pada Tabel 1 menunjukkan pada sebelum dan sesudah dilakukan perlakuan menghasilkan perbedaan denyut nadi kerja.

Hasil penelitian menunjukkan bahwa rerata beban kerja pada pekerja bengkel pengamplas cat motor sebelum dilakukan perlakuan adalah 40,22 $\pm 3,81 \mathrm{dpm}$, sedangkan rerata beban kerja pada pekerja bengkel pengamplas cat motor setelah dilakukan perlakuan berupa redesain alat kerja pengamplas dan hand stretching adalah $36,83 \pm 2,56 \mathrm{dpm}$ sehingga terjadi penurunan beban kerja sebesar 30,3\%. 


\section{Nyeri Muskuloskeletal}

Nyeri muskuloskeletal pada subjek diukur dengan menggunakan Visual Analog Scale (VAS). Pengukuran tersebut bersifat subjektif. Sebelum memulai pekerjaan pada masing-masing periode, seluruh subjek diminta menunjukkan besar skala pada Visual Analog Scale yang mewakili nilai nyeri muskuloskeletal yang dialami sebelum melakukan kerja hasil uji perbedaan skor nyeri, Hasil yang diperoleh setelah dilakukan uji. Data nyeri muskuloskeletal pekerja pengamplas cat motor tidak berdistribusi normal, sehingga untuk menganalisis perbedaan efek perlakuan dengan menggunakan uji Wilcoxon pada tingkat kepercayaan $\alpha=0,05$ disajikan pada Tabel 2

Tabel 2

Hasil Perbedaan Nyeri Musculoskeletal

\begin{tabular}{|c|c|c|c|c|c|}
\hline Variabel & $\begin{array}{c}\text { Rerata } \\
\pm \mathrm{SB}\end{array}$ & $\begin{array}{c}\text { Rerata } \\
\pm \text { SB }\end{array}$ & $\begin{array}{c}\text { Nilai } \\
\text { z }\end{array}$ & $\begin{array}{l}\text { Nilai } \\
\text { p }\end{array}$ & $\begin{array}{c}\text { Keterang } \\
\text { an }\end{array}$ \\
\hline $\begin{array}{l}\text { Nyeri } \\
\text { Muskuloskeletal } \\
(\text { Pre })\end{array}$ & $\begin{array}{c}4,17 \pm \\
0,58\end{array}$ & $\begin{array}{c}3,92 \pm \\
0,67\end{array}$ & $-1,73$ & 0,083 & $\begin{array}{c}\text { Tidak } \\
\text { Berbeda } \\
\text { bermakna }\end{array}$ \\
\hline $\begin{array}{l}\text { Nyeri } \\
\text { Muskuloskeletal } \\
(\text { Post })\end{array}$ & $\begin{array}{c}4,50 \pm \\
0,67\end{array}$ & $\begin{array}{c}2,08 \pm \\
0,29\end{array}$ & $-3,13$ & 0,002 & $\begin{array}{c}\text { Berbeda } \\
\text { bermakna }\end{array}$ \\
\hline
\end{tabular}

Hasil penelitian lain yang sejalan mengenai peregangan sebelum melakukan kerja adalah penelitian yang dilakukan oleh Irwanti (2011), yang melakukan penelitian mengenai hand stretching dapat meredakan sakit muskuloskeletal,

\section{Produktiitas Kerja}

Hasil analisis normalitas data menunjukkan bahwa data skor produktivitas berdistribusi normal disajikan pada Tabel 3

Tabel 3

Hasil Perbedaan Produktivitas Kerja

\begin{tabular}{|c|c|c|c|c|}
\hline \multirow{2}{*}{ Variabel } & Periode I & Periode II & $\begin{array}{l}\text { Nila } \\
\text { i t }\end{array}$ & $\begin{array}{cc} & \mathrm{Ke} \\
\text { Nil } & \text { ter } \\
\text { ai } & \text { an }\end{array}$ \\
\hline & $\begin{array}{l}\text { Rerata } \pm \\
\text { SB }\end{array}$ & Rerata $\pm S$ & & \\
\hline $\begin{array}{l}\text { Produktivitas } \\
\text { Kerja }\end{array}$ & $\begin{array}{c}0,019 \\
\pm \\
0,003\end{array}$ & $\begin{array}{c}0,031 \pm \\
0,004\end{array}-9,66$ & 0,0001 & $\begin{array}{c}\text { Berbe } \\
\text { da } \\
\text { berma } \\
\text { kna }\end{array}$ \\
\hline
\end{tabular}

Seperti yang di saj1kan pada tabel 3,

Luaran (output) adalah rerata jumlah badan motor yang dapat diselesaikan oleh pekerja pengamplas cat motor per satuan waktu, sedangkan masukan (input) adalah beban yang diterima pekerja pengamplas cat motor berupa nadi kerja dan waktu (time) adalah waktu yang diperlukan untuk menyelesaikan pekerjaan pengamplasan (3 jam atau 180 menit), Penelitian yang sejalan dengan Daryono (2016), dilakukan pada pekerja sablon menyatakan bahwa terjadi peningkatan produktivitas kerja setelah dilakukan redesain alat kerja rakel serta peregangan aktif dapat meningkatkan 
Jurnal Ergonomi Indonesia (The Indonesian Journal of Ergonomic)
Vol.4, No.2 : 1 Juli-Desember 2018 produktivitas kerja sebesar 45,5\% dengan sebelum dilakukan redesain alat kerja.

\section{Lingkungan Kerja}

Kondisi lingkungan yang diukur di lokasi penelitian adalah kondisi ruangan terbuka tempat dilangsungkannya pekerjaan pengamplasan cat motor yang meliputi suhu basa, suhu kering, kebisingan, dan intensitas penerangan, sedangkan kelembaban relatif dicari dalam diagram psikometri. Hasil uji beda menggunakan Kolmogorov-Smirnov tersaji pada Tabel 4

\section{Tabel 4}

Perbedaan Kondisi Lingkungan Tempat

\begin{tabular}{|c|c|c|c|c|c|c|c|}
\hline \multirow{2}{*}{ Variabel } & \multirow{2}{*}{$\mathrm{n}$} & \multicolumn{2}{|c|}{ Periode I } & \multicolumn{2}{|c|}{ Periode II } & \multirow{2}{*}{$\begin{array}{l}\text { Nila } \\
\text { i }\end{array}$} & \multirow{2}{*}{$\begin{array}{l}\text { Nila } \\
\text { i p }\end{array}$} \\
\hline & & $\begin{array}{c}\text { Rera } \\
\text { ta }\end{array}$ & SB & $\begin{array}{c}\text { Rera } \\
\text { ta }\end{array}$ & SB & & \\
\hline Suhu Basah $\left({ }^{\circ} \mathrm{C}\right)$ & 3 & $\begin{array}{c}25,2 \\
5\end{array}$ & 1,39 & $\begin{array}{c}25,0 \\
8\end{array}$ & 1,04 & .121 & .914 \\
\hline Suhu Kering $\left({ }^{\circ} \mathrm{C}\right)$ & 3 & $\begin{array}{c}30,0 \\
0\end{array}$ & 0,50 & $\begin{array}{c}30,1 \\
3\end{array}$ & 0,42 & $\begin{array}{r}- \\
.658\end{array}$ & .578 \\
\hline $\begin{array}{l}\text { Intensitas } \\
\text { Kebisingan } \\
\text { (dBA) }\end{array}$ & 3 & $\begin{array}{c}84,2 \\
5\end{array}$ & 1,14 & $\begin{array}{c}83,9 \\
0\end{array}$ & 0,41 & .820 & .498 \\
\hline $\begin{array}{l}\text { Penerangan } \\
\text { (Lux) }\end{array}$ & 3 & $\begin{array}{c}448, \\
67\end{array}$ & 1,53 & $\begin{array}{c}450 \\
00\end{array}$ & 4,36 & $\begin{array}{r}- \\
.800\end{array}$ & .508 \\
\hline $\begin{array}{l}\text { Kelembaban } \\
\text { Relatif }(\%)\end{array}$ & 3 & $\begin{array}{c}78,9 \\
2\end{array}$ & 0,76 & $\begin{array}{c}78,7 \\
9\end{array}$ & 1,28 & .435 & .706 \\
\hline
\end{tabular}

Kelembaban relatif $78,92 \%$ dan sesudah perlakuan $78,79 \%$ diharapkan tidak berpengaruh terhadap jalannya penelitian karena lingkungan tersebut sudah teradaptasi sehingga tergolong dalam kategori nyaman. Intensitas kebisingan tempat kerja dapat mengganggu kenyamanan, ketenangan kerja, dan mengakibatkan penurunan daya dengar yang menyebabkan ketulian. Nilai ambang batas kebisingan yaitu $80 \mathrm{dBA}$ sehingga tidak sampai mengganggu aktivitas pengamplasan cat motor. Disebutkan tidak semua bunyi yang keras atau gaduh dirasakan sebagai gangguan, tergantung perasaan dan kebiasaan indiidu masing-masing. tingkat kebisingan sebelum perlakuan dan sesudah perlakuan didapati bahwa kebisingan yang terjadi pada tempat pengamplasan tidak memberi efek fisiologis pada subjek selama penelitian. Intensitas kebisingan ini sesuai dengan ambang batas tertinggi yang masih dapat diterima subjek tanpa mengakibatkan gangguan daya dengar yang tetap untuk waktu kerja tidak lebih dari 8 jam sehari adalah 85 dBA. Suhu lingkungan dari hasil pengukuran diperoleh suhu basah sebelum 
perlakuan dengan rerata dan simpang baku $25,25+1,39^{\circ} \mathrm{C}$ hampir sama dengan suhu basah sesudah perlakuan rerata $25,08+1,04^{\circ} \mathrm{C} . \quad$ Suhu tersebut kategori nyaman, karena kenyamanan suhu basah ruang kerja di Indonesia antara $22-28^{\circ} \mathrm{C}$. Suhu kering sebelum perlakuan diperoleh rerata $30,00+0,05^{\circ} \mathrm{C}$ kondisinya hampir sama dengan suhu kering sesudah perlakuan dengan rerata $30,13+0,42^{\circ} \mathrm{C}$.

\section{DAFTAR PUSTAKA}

1. Anderson, B. 2010. Stretching in The Office. Serambi Ilmu Semesta. Jakarta.

2. Arimbawa, I.M.G. 2009. Redesain Peralatan Kerja Secara Ergonomis Meningkatkan Kinerja Pembuat Minyak Kelapa Tradisional di Kecamatan Dawan Klungkung. Disertasi. Program Pascasarjana S3 Ilmu Kedokteran Universitas Udayana.

3. Colton,T. 1985. Statistics in Medicine. Diterjemahkan oleh Sanusi, R: Statistika Kedokteran, Fakultas Kedokteran Universitas Gadjah Mada. Jogyakarta:Gadjah Mada University Press.

4. Daryono. 2016. Redesain Rakel dan Pemberian Peregangan Aktif Menurunkan Beban Kerja dan Keluhan
Muskuloskeletal serta Meningkatkan Produktiitas kerja Pekerja Sablon pada Industri Sablon Surya Bali di Denpasar . Tesis. Denpasar: Universitas Udayana.

5. Irwanti, N. K. D. 2011. Peregangan Otot di Sela Pembelajaran Mengurangi Kebosanan, Kelelahan dan Keluhan Muskuloskeletal Peserta Didik Kelas X, SMK Pariwisata Triatma Jaya Badung. Tesis. Denpasar: Universitas Udayana.

6. Manuaba, A. 1998. Dengan Desain yang Aman Mencegah Kecelakaan dan Cedera. Bunga Rampai Ergonomi: Vol I. Program Pascasarjana Ergonomi-Fisiologi Kerja, Universitas Udayana, Denpasar.

7. Pocock, S.J. 2008. Clinical Trial. A Practical Approach: the size of clinical trial.Hichester: Jhon Wiley \& Sons.

8. Richardson, G., Taylor, G., dan Lanis, R. 2013. The Impact Of Board Of Director Oversight Characteristics On Corporate Tax Aggressiveness: An Empirical Analysis. Journal Accounting and Public Policy. 32 (2013) 68-88.

9.Soedarma. 2012. Sosiologi Untuk Kesehatan.edisi 7. Salemba Medika, Jakarta.

10.Wibowo, A.E., Djojo, A. 2012, Aplikasi Praktis SPSS dalam Penelitian, Edisi Ke Dua, Penerbit Gava Media,Yogyakarta 